\title{
Cognitive health of the elderly
}

\begin{abstract}
A substantial proportion of the world's elderly population resides in the developing countries. It is noted that there has been an increase in longevity for these elderly and as a consequence their health profiles have changed. For example, it has been observed that increased longevity led to higher prevalence of age related neurological disorder like dementia. In India, community based studies on cognitive impairment and associated lifestyle factors are very few and such studies in the eastern part of the country is virtually lacking.
\end{abstract}

In view of the above, a comparative profile of cognitive function between rural and urban elderly of West Bengal, India, has been reported in the present study. The study has also been purported to identify the role of socio-demographic factors on cognitive function.

A structured demographic questionnaire was used for collection of socio-demographic data and $\mathrm{MMSE}^{1}$ was canvassed for collection of data on cognitive function from a sample of urban and a rural elderly population. The study sample includes 381 elderly of both sexes, taken from both urban (176) and rural (205) settings in the Indian State of West Bengal with an age range of 65 to 79years (mean age 70.6years). Results of the study indicate that the cognitive impairment is significantly higher among the rural elderly than their urban counterparts, irrespective of sex. The results also demonstrate that more adversities in cognitive function occur in female gender, irrespective of area of residence. Multinomial logistic regression model reveal that age, sex, marital status, self earning, family earning, family size and number of living children are the important predictors of cognitive impairment in the study population.

Keywords: elderly, cognitive function, socio-demographic factors, area of residence
Volume I Issue I - 2014

Moumita Maity, Barun Mukhopadhyay

Biological Anthropology Unit, Indian Statistical Institute, India

Correspondence: Moumita Maity, Biological Anthropology Unit, Indian Statistical Institute, 203, Barrackpore Trunk Road, Kolkata,West Bengal 700108, India, Tel 91-9832218967, Email moumita.maity05@gmail.com

Received: April 17, 2014 | Published: May 16, 2014

\section{Introduction}

A growing aging population is observed at present in demographic profile of India. From a public health perspective, the population aging is directing to a fast increase in the number of elderly throughout the world. ${ }^{2}$ It is well documented that the aged population from developing countries are growing faster than the developed countries. ${ }^{3}$ In India, the aging population above 60 years has been estimated to almost double-up from $7.7 \%$ in 2001 to $12.30 \%$ in 2025 and the number of elderly people will be nearly 150 million. ${ }^{4}$

Cognitive function is "an intellectual process by which one becomes aware of, perceives or comprehends ideas. It involves all aspects of perception, thinking, reasoning, and remembering".5 Neurological disorders are common disorders resulting in disabilities and losses of productive life. Cognitive dysfunction or dementia is a common neurological disorder and a significant public health problem as it is an important cause of disability and mortality among elderly population. A neurologically degenerative disorder is the underlying cause in case of majority of significant cognitive decline. ${ }^{6}$ Prince estimated that 24.3 million people worldwide suffered from dementia i.e. severe loss in cognitive function and it is further estimated that the number increases on an average at the rate of 4.6 million per year. ${ }^{8}$ They also estimated the prevalence of dementia in South Asia including India to be $1.9 \%$ among the elderly aged sixty years and above with an annual incidence of 4.3/1000. It is also estimated that by 2020 the total number of dementia cases will reach 3.6 million and 7.5 million by 2040 in this particular part of the globe. It is also to be noted that increase of dementia cases were estimated 3-4times higher in developing countries than in developed countries. It has also been documented by different studies in Indian populations that increasing age is an important indicator of higher prevalence rate of dementia. ${ }^{9-12}$
Though few neurological studies have been carried out among both urban and rural populations of India ${ }^{13-15}$ nevertheless prevalence estimates of cognitive impairment (characteristic of dementia), have not been studied in individual communities. A few reports exist on cognitive impairment and associated factors in developing countries where a bulk of the world's population resides. As cognitive impairment is the indicator of the presence of underlying or incipient disorders such as Alzheimer's disease (AD) and other dementias, it may remain undetected in these populations.

Though cognitive mishaps are related to the older age, very few studies have been conducted in India including West Bengal. Again, the community based studies from India have documented crude prevalence rates of dementia varying from 84 to 350 per 1000 among population above the age of 55years. ${ }^{11,12,16-20}$ An Indo-US cross national epidemiological study on dementia has been carried out to compare the prevalence between two rural populations of India and the US ${ }^{21}$. A South India based study on rural population has found about 3.5 percent of dementia prevalence which increased with increasing age ${ }^{20}$. Similar prevalence rate of dementia has been found in another study from Kerala. ${ }^{22}$ Chandra et al. ${ }^{15}$ carried out a study on neurologic factors associated with cognitive impairment. A study by Vas et al., ${ }^{12}$ among the urban South Indians showed lower prevalence of dementia than that in urban populations from developed countries, and it furthermore showed that prevalence rate was higher among older age group compared to their younger aged counterparts. Rajkumar et al., ${ }^{20}$ observed that prevalence of dementia increased with age, again prevalence was higher among this rural South Indian community than that found in the urban settings. Another Indo-US cross-sectional study by Chandra et al. ${ }^{23}$ found higher prevalence of dementia among rural Indians than their US community counterparts. They also found that the prevalence rate is becoming higher with increment of age and it is not related with gender. 
Present study has been conducted among the elderly of rural and urban West Bengal, India, as the rural-urban comparison on cognitive health of a particular community has not been attempted earlier in this Indian State. On the above backdrop, present study attempts to

i. Evaluate cognitive functioning among the Bengali residential groups (rural and urban) of West Bengal. ii. To examine the effects of socio-demographic factors and social ties (social support and social network) on cognitive function in these groups.

\section{Material and methods}

\section{Study settings}

The present study was conducted on middle class Bengalis inhabiting the Salt Lake City, Bidhannagar municipality, North 24 Parganas, selected as urban study group and five villages in a remote rural setting under the Horkhali Grampanchayat of Haldia subdivision of Purba Medinipur district, West Bengal constituting rural groups. In both the settings, middle class Bengalis is the predominant group. The study was conducted on about nine blocks from three sectors of the Salt Lake City and on the other hand randomly chosen five villages from Horkhali Grampanchayat, under Sutahata block.

\section{Sampling}

From each systematically selected block from urban locale, individuals of both sexes aged between 65 and 79 years have been identified through the latest electoral roll available. Each individual within the required age range was invited to participate in the study. For the rural locale, from a total of five selected villages, a list of elderly of both sexes was made, aged 65-79years. After preparing the list of individuals from all the selected villages each elderly of the said age group was approached to take part in the study. The purpose of the study was described elaborately to each of the approached elderly from the individual list. Those who willingly wanted to participate in the study were selected. None of the study participants was under any treatment for any mental health problems and none was taking medication for any mental disorder.

\section{Study population}

Mean age of the study group combining urban and rural participants is $70.9 \pm 4.7$ years, while for Rural it is $70.7 \pm 4$.8years and for Urban it is $71.0 \pm 4.5$ years. A chi-square test was carried out to determine the difference in the proportion of male and female participants for both rural and urban groups. Result of the test shows that difference was not statistically significant i.e., the study sample is almost equally distributed for sex across the groups. Data were collected between 2009 and 2010, simultaneously from both the communities. The study population consists of 176 urban (male: 93 and female: 83) and 205 rural (male: 103 and female: 102) participants. The study was approved by the ethics committee of the Indian Statistical Institute, Kolkata. Written informed consent to express willingness to participate in the study was obtained from all elderly individuals after the objectives and methods of the study were explained to them.

\section{Socio-demographic measures}

Information on socio-demographic characteristics was collected using a pretested questionnaire. This questionnaire includes information on demographic aspects such as age, sex, marital status, family size, number of living offspring, living arrangement and socioeconomic aspects such as educational status, employment status, self income and family income. Participants were categorized as "younger old" (65-71yrs) and "older old" (72-79yrs). "Married' and "Unmarried/widow/widower" were the two categories for marital status. Total family size was categorized as " $<5$ members" and " $\geq 5$ members". Total number of living offspring was categorized as " $<3$ offspring" and " $\geq 3$ offspring". For each study participant, number of surviving (living) offspring irrespective of their staying together was noted. Living arrangement was categorized into two groups: "living with offspring" and "living without offspring".

Participants were subdivided into two educational categories on the basis of their formal educational attainment. For rural study participants, there have been two categories viz. "non-educated" meaning not exposed to any formal schooling and "educated" meaning having to at least one year exposure to formal schooling. Again for the urban study participants there have been two categories viz. "below graduation" and "graduation and above". It is to be noted that expectedly, there has been none but one female remained uneducated in the urban group. Occupational status of the study participants was categorized into two occupational groups, i.e., "pension holder/ peasant or labor" and "home maker/idler". Self earning is categorized as "lower self earning" ( $<$ Rs. 400 per month in case of rural group and $<$ Rs. 5000 per month in case of urban group) and "higher self earning" ( $\geq$ Rs. 400 per month in case of rural group and $\geq$ Rs. 5000 per month in case of urban group). Family earning is categorized as "lower family earning" ( $<$ Rs. 2000 per month in case of rural group and $<$ Rs. 30,000 per month in case of urban group) and "higher family earning" ( $\geq$ Rs. 2000 per month in case of rural group and $\geq$ Rs. 30,000 per month in case of urban group).

\section{Social ties (social support and social network)}

Norbeck Social Support Questionnaire (NSSQ) ${ }^{24}$ was used for collection of data on social support. It is an important social support questionnaire that measures several components related to the functional properties of social support. These properties include emotional and tangible support, loss of supportive relationships support from other sources etc. The items are rated on a 5-point Likert type scale. Scores were categorized into three social support categories i.e., 'total functional', 'total network properties' and 'total loss'.

Information on social network was collected by using Social Network Index (SNI) ${ }^{25}$. Scoring of the Social Network Index pertains to three domains namely

i) Number of high-contact roles

ii) Number of people in social network and

iii) Number of embedded networks. The domains are calculated by adding obtained scores.

\section{Cognitive function}

Information on cognitive function was obtained following the standard questionnaire named MMSE. ${ }^{1}$ This cognitive scale offers a quick and simple way to quantify cognitive function and screen for cognitive loss. It tests the individual's orientation, attention, calculation, recall language and motor skills. Each section of the test involves a related series of questions or commands. The individual receives one point for each correct answer. The score of cognitive function categorized into three categories as uncertain cognitive impairment (24-30), mild to moderate cognitive impairment (18-23) and severe cognitive impairment (0-17). 


\section{Reliability test}

Cronbach's alpha is a coefficient of internal consistency. It is commonly used to estimate the reliability of psychometric test for a scale. A scale or test cannot be valid if it is not reliable. A good scale will also be internally consistent in that all items make a significant contribution to the final score or rating. The level of reliability of an instrument is traditionally measured by a Cronbach's alpha coefficient. Alpha value of $>0.40$ of a psychological scale considered as a good consistency ${ }^{26}$ and value greater $>0.70$ considered a threshold reliability value for general survey studies. ${ }^{27}$ For the present study sample alpha is 0.83 .

\section{Statistical analyses}

Descriptive statistics was done to understand the trend in the socio-demographic profiles and cognitive function by place of residence (urban and rural). Contingency chi square test was done to compare the population distribution by socio-demographic variables and cognitive values between residential settings. It was also done to compare the severity of cognitive mishap by age groups between sex and residential settings and also by socio-demographic variables. t-test was performed to compare the means of the cognitive scores between urban and rural settings.

Multinomial logistic regression model was utilized to find out the effect of socio-demographic factors on cognitive function. Multinomial logistic regression allowed us to examine which sociodemographic factors affected the odds of having a high score on cognitive function. The covariates in the equation are age groups, sex, place of residence, marital status, family size, total number of living offspring, level of education, occupational status, self earning, family earning, family size and living arrangement.

\section{Results}

\section{Socio-demographic characteristics}

The distribution of study participants by socio-demographic variables is presented in (Table 1). The Table 1 reveals that majority of the study participants from both the settings are ever married, as expected. Percentage of married participants is significantly higher in urban setting as compared to rural setting. Urban study participants are showing significantly higher prevalence in total family size of $<5$ members, while rural participants have showed higher prevalence in family size of $\geq 5$ members. It appears that a significant majority of the study participants from rural setting have more than and equal to 3 offspring while majority of the urban participants have less than 3 offspring. It also appears that the overwhelming majority of the rural study participants are living with their offspring. Among the urban study participants, about $50 \%$ of them live with their offspring when sexes are combined. Majority of the urban study participants are educated. On the other hand, overall about $60 \%$ of the rural elderly are non-educated. As expected, an overwhelming majority of the urban study participants are pension holder while a majority of the rural participants are home maker/idler. Rural study participants showed higher percentage in lower self earning category, whereas more than $60 \%$ of the urban study participants are under higher self-earning category.

Values in parentheses are percentages; ${ }^{*} \mathrm{p} \leq 0.05, * * \mathrm{p} \leq 0.01$

Cognitive function scores

Table 2 shows mean, standard deviation and results of the test of significance (t-test) in respect of cognitive function score. Urban study participants show higher mean scores compared to their rural counterparts, irrespective of sex while rural males show higher cognitive function score, irrespective of age group compared to rural females. Sex differences are significant for both the age groups of rural study group. This table also shows that the rural study participants have significantly higher cognitive scores compared to their urban counterparts irrespective of age.

Values in parentheses are percentages; ${ }^{*} \mathrm{p} \leq 0.05 ;{ }^{* *} \mathrm{p} \leq 0.01$

Prevalence of cognitive impairment categories by age groups, sex and residential settings has been presented in (Table 3). Prevalence of severe cognitive impairment is relatively high among the rural elderly, irrespective of sex. However, urban elderly has shown marginally higher prevalence in uncertain cognitive impairment compared with other cognitive impairment categories. Females have shown significantly higher prevalence in severe cognitive impairment in $\left(\chi^{2}=18.41^{* *}\right)$ total population.

Values in parentheses are percentages; $* \mathrm{p} \leq 0.05 ; * * \mathrm{p} \leq 0.01 ; \mathrm{CI}=$ Cognitive Impairment

Furthermore, Table 3 depicts the higher prevalence of severe cognitive impairment among rural study participants irrespective of sex (male: $24.27 \%$, female: $55.88 \%$ ) while majority of the urban study participants has shown high prevalence of uncertain cognitive impairment (male: 97.59\%, female: 97.85\%). Rural females showed significantly higher prevalence of severe cognitive impairment than that of their male counterparts. In both the sexes, a significant ruralurban difference in prevalence of cognitive impairment has been found.

\section{Socio-demographic correlates of cognitive functionM}

The relationship between cognitive impairment categories and socio-demographic variables has been presented in (Table 4). Table 4 reveals that the chances of severe cognitive impairment that is significantly higher among the females, rural study participants, unmarried/widow /widower, $>5$ family members, $\geq 3$ offspring, staying with children, non-educated/ below graduation, homemaker/ idler, lower self earning and lower family earning.

Values in parentheses are percentages; $* \mathrm{p} \leq 0.05 ; * * \mathrm{p} \leq 0.01$; CI $=$ Cognitive Impairment

Table 5 depicts association of cognitive impairment with sociodemographic covariates. Participant's sex is an important factor to associate with cognitive impairment among the rural study group. For example, rural females are about three times more likely to have mild to moderate cognitive impairment as compared to uncertain cognitive impairment. It is about twelve times more likely in favor of severe cognitive impairment among rural females as compared to uncertain cognitive impairment.

${ }^{*} \mathrm{p} \leq 0.05 ; * * \mathrm{p} \leq 0.01 ;$ Reference category is uncertain cognitive impairment (Score: 24-30).

Logistic regression analysis is done for examining association of cognitive function with social support and social network, the results of which are shown in (Table 6). Total network properties are significantly less likely in favor of mild to moderate and severe cognitive impairment of rural study participants as compared to uncertain cognitive impairment. Number of high contact role of social network is significantly less likely in favor of severe cognitive impairment among the rural elderly.

${ }^{*} \mathrm{p} \leq 0.05 ; * * \mathrm{p} \leq 0.01$, Reference category is uncertain cognitive impairment (24-30). 
Table I Demographic and socio-economic characteristics: rural and urban participants

\begin{tabular}{|c|c|c|c|c|}
\hline Variables & Rural (n = 205) & Urban $(n=176)$ & Total $(n=38 I)$ & $\chi 2$ \\
\hline \multicolumn{5}{|l|}{ Age Group } \\
\hline Younger old & $142(69.27)$ & $109(61.93)$ & $25 \mid(65.88)$ & 2.27 \\
\hline Older old & $63(30.73)$ & $67(38.07)$ & $130(34.12)$ & \\
\hline \multicolumn{5}{|l|}{ Sex } \\
\hline Male & $103(50.24)$ & $93(52.84)$ & $196(51.44)$ & 0.26 \\
\hline Female & $102(49.76)$ & $83(47.16)$ & $185(48.56)$ & \\
\hline \multicolumn{5}{|l|}{ Marital Status } \\
\hline Married & $128(62.44)$ & $138(78.4 \mid)$ & $266(69.82)$ & $11.46 * *$ \\
\hline Unmarried/widow/widower & $77(37.56)$ & $38(21.59)$ & $115(30.18)$ & \\
\hline \multicolumn{5}{|l|}{ Family Size } \\
\hline$<5$ members & $60(29.27)$ & $127(72.16)$ & $187(49.08)$ & $69.71 * *$ \\
\hline$\geq 5$ members & $145(70.73)$ & $49(27.84)$ & $194(50.92)$ & \\
\hline \multicolumn{5}{|l|}{ Number of Living Offspring } \\
\hline$<3$ offspring & $16(7.80)$ & $163(92.61)$ & $179(46.98)$ & $273.44^{* *}$ \\
\hline$\geq 3$ offspring & $189(92.20)$ & $13(7.39)$ & $202(53.02)$ & \\
\hline \multicolumn{5}{|l|}{ Living Arrangement } \\
\hline Staying with children & I8I (88.29) & $86(48.86)$ & $267(70.08)$ & $70.21 * *$ \\
\hline Staying without children & $24(11.7 I)$ & $90(51.14)$ & $114(29.92)$ & \\
\hline \multicolumn{5}{|l|}{ Level of Education } \\
\hline Non-educated/ below graduation & $124(60.49)$ & $19(10.80)$ & $143(37.53)$ & $99.74 * *$ \\
\hline Educated/ Graduation and above & $81(39.5 \mathrm{I})$ & $157(89.20)$ & $238(62.47)$ & \\
\hline \multicolumn{5}{|l|}{ Occupation } \\
\hline Pension holder/ peasant or labor & $82(40.00)$ & $124(70.45)$ & $206(54.07)$ & $35.37 * *$ \\
\hline Homemaker/idler & $123(60.00)$ & $52(29.55)$ & $175(45.93)$ & \\
\hline \multicolumn{5}{|l|}{ Self Earning } \\
\hline Lower self earning & I I 7 (57.07) & $64(36.36)$ & I8I (47.5I) & $16.29 * *$ \\
\hline Higher self earning & $88(42.93)$ & $112(63.64)$ & $200(52.49)$ & \\
\hline \multicolumn{5}{|l|}{ Family Earning } \\
\hline Lower family earning & $105(51.22)$ & $85(48.30)$ & $190(49.87)$ & 0.32 \\
\hline Higher family earning & $100(48.78)$ & $91(51.70)$ & $191(50.13)$ & \\
\hline
\end{tabular}

Table 2 Descriptive statistics (mean and standard deviation) and test of significance of difference in mean values of cognitive function scores, by age, sex and area of residence

\begin{tabular}{|c|c|c|c|c|c|c|c|}
\hline \multirow[b]{2}{*}{ Age Group } & \multicolumn{2}{|c|}{ Rural (n = 205) } & \multicolumn{2}{|c|}{ Urban $(n=\mid 76)$} & \multicolumn{2}{|c|}{ Total $(n=38 I)$} & \multirow{2}{*}{$\begin{array}{l}\text { t-value } \\
\text { Rural-Urban }\end{array}$} \\
\hline & Male & Female & Male & Female & Rural & Urban & \\
\hline & $(n=103)$ & $(n=102)$ & $(n=93)$ & -83 & & & \\
\hline Younger Old & $19.95 \pm 4.22$ & $17.53 \pm 3.92 * *$ & $28.42 \pm 1.68$ & $28.06 \pm 1.77$ & $|8.57 \pm 4.2|$ & $28.20 \pm 1.75$ & $22.43 * *$ \\
\hline Older Old & $20.26 \pm 4.88$ & $12.52 \pm 5.27 * *$ & $27.84 \pm 1.45$ & $27.59 \pm 1.84$ & $17.68 \pm 6.19$ & $27.78 \pm 1.55$ & $12.94 * *$ \\
\hline Total & $20.08 \pm 4.48$ & $16.50 \pm 4.67 * *$ & $28.11 \pm 1.58$ & $27.96 \pm 1.80$ & $18.30 \pm 4.90$ & $28.04 \pm 1.69$ & $25.11 * *$ \\
\hline
\end{tabular}

Table 3 Prevalence of cognitive impairment categories by age, sex and area of residence

\begin{tabular}{|c|c|c|c|c|c|c|c|c|}
\hline & \multicolumn{4}{|l|}{ Male } & \multicolumn{4}{|l|}{ Female } \\
\hline & Uncertain $\mathbf{C l}$ & Mild to moderate $\mathrm{Cl}$ & Severe $\mathbf{C l}$ & $\chi^{2}$ & Uncertain $\mathrm{Cl}$ & Mild to moderate $\mathrm{Cl}$ & Severe $\mathbf{C l}$ & $\chi^{2}$ \\
\hline \multicolumn{9}{|l|}{ Rural } \\
\hline Younger old & $15(14.56)$ & $34(33.01)$ & $12(11.65)$ & 2.62 & $6(5.88)$ & $35(34.31)$ & $40(39.22)$ & $7.07 *$ \\
\hline Older old & $12(11.65)$ & $17(16.50)$ & $13(12.62)$ & & - & $4(3.92)$ & $17(16.67)$ & \\
\hline All ages & $27(26.21)$ & $5 \mathrm{I}(49.5 \mathrm{I})$ & $25(24.27)$ & & $6(5.88)$ & $39(38.24)$ & $57(55.88)$ & \\
\hline \multicolumn{9}{|l|}{ Urban } \\
\hline Younger old & $42(45.16)$ & I (I.08) & - & & $65(78.3 \mathrm{I})$ & $\mathrm{I}(\mathrm{I} .20)$ & - & \\
\hline Older old & $49(52.69)$ & I (I.08) & - & & $16(19.28)$ & $\mathrm{I}(\mathrm{I} .20)$ & - & \\
\hline All ages & 91 (97.85) & $2(2.15)$ & - & & 81 (97.59) & $2(2.40)$ & - & \\
\hline \multicolumn{9}{|l|}{ Total } \\
\hline Younger old & $57(29.08)$ & $35(17.86)$ & $12(6.12)$ & 4.91 & 7I (38.38) & $36(19.46)$ & $40(21.62)$ & 5.01 \\
\hline Older old & $61(31.12)$ & $18(9.18)$ & $13(6.63)$ & & $16(8.65)$ & $5(2.70)$ & $17(9.19)$ & \\
\hline All ages & $118(60.20)$ & $53(27.04)$ & $25(12.76)$ & & 87 (47.03) & $4 I(22.16)$ & $57(30.8 I)$ & \\
\hline \multicolumn{9}{|l|}{ Rural-Urban } \\
\hline
\end{tabular}


Table 4 Cognitive impairment and socio-demographic variables

\begin{tabular}{|c|c|c|c|c|}
\hline Variables & Uncertain Cl & Mild-Moderate Cl & Severe $\mathbf{C l}$ & $\chi^{2}$ \\
\hline \multicolumn{5}{|l|}{ Age Group } \\
\hline Younger old & $128(51.00)$ & 7I (28.29) & $52(20.72)$ & \multirow[t]{2}{*}{5.2} \\
\hline Older old & $77(59.23)$ & $23(17.69)$ & $30(23.08)$ & \\
\hline \multicolumn{5}{|l|}{ Sex } \\
\hline Male & I I 8 (60.20) & $53(27.04)$ & $25(12.76)$ & \multirow[t]{2}{*}{$|8.4| * *$} \\
\hline Female & $87(47.03)$ & $4 I(22.16)$ & $57(30.8 I)$ & \\
\hline \multicolumn{5}{|l|}{ Area of Residence } \\
\hline Rural & $33(16.10)$ & $90(43.90)$ & $82(40.00)$ & \multirow[t]{2}{*}{$254.20 * *$} \\
\hline Urban & I 72 (97.73) & $4(2.27)$ & - & \\
\hline \multicolumn{5}{|l|}{ Marital Status } \\
\hline Married & 159 (59.77) & $63(23.68)$ & $44(16.54)$ & \multirow[t]{2}{*}{$16.34 * *$} \\
\hline Unmarried/widow/widower & $46(40.00)$ & $31(26.96)$ & $38(33.04)$ & \\
\hline \multicolumn{5}{|l|}{ Family Size } \\
\hline$<5$ members & |3| (70.05) & $33(17.65)$ & $23(12.30)$ & \multirow[t]{2}{*}{$39.88 * *$} \\
\hline$>5$ members & $74(38.14)$ & $6 I(31.44)$ & $59(30.4 I)$ & \\
\hline \multicolumn{5}{|l|}{ Number of Living Offspring } \\
\hline$<3$ offspring & $162(90.50)$ & $9(5.03)$ & 8 (4.47) & \multirow[t]{2}{*}{$182.93 * *$} \\
\hline$\geq 3$ offspring & $43(21.29)$ & $85(42.08)$ & $74(36.63)$ & \\
\hline \multicolumn{5}{|l|}{ Living Arrangement } \\
\hline Staying with children & I I 4 (42.70) & $76(28.46)$ & $77(28.84)$ & \multirow[t]{2}{*}{$47.87 * *$} \\
\hline Staying without children & 91 (79.82) & I8 (I5.79) & 5 (4.39) & \\
\hline \multicolumn{5}{|l|}{ Level of Education } \\
\hline Non-educated/ below graduation & $33(23.08)$ & $53(37.06)$ & $57(39.86)$ & \multirow[t]{2}{*}{$90.19 * *$} \\
\hline Educated/ Graduation and above & 172 (72.27) & $4 I(I 7.23)$ & $25(10.50)$ & \\
\hline \multicolumn{5}{|l|}{ Occupation } \\
\hline Pension holder/ peasant or labor & 137 (66.50) & $44(21.36)$ & $25(12.14)$ & \multirow[t]{2}{*}{$33.80 * *$} \\
\hline Homemaker/idler & $68(38.86)$ & $50(28.57)$ & $57(32.75)$ & \\
\hline \multicolumn{5}{|l|}{ Self Earning } \\
\hline Lower self earning & 81 (44.75) & $46(25.4 I)$ & $54(29.83)$ & \multirow[t]{2}{*}{$16.40 * *$} \\
\hline Higher self earning & $124(62.00)$ & $48(24.00)$ & $28(\mid 4.00)$ & \\
\hline \multicolumn{5}{|l|}{ Family Earning } \\
\hline Lower family earning & $96(50.33)$ & $48(25.26)$ & $46(24.28)$ & \multirow[t]{2}{*}{2.08} \\
\hline Higher family earning & $109(57.07)$ & $46(24.08)$ & $36(18.85)$ & \\
\hline
\end{tabular}

Table 5 Results of logistic regression analysis showing association between socio demographic variables and cognitive impairment categories (odds ratio and $95 \% \mathrm{Cl})$

\begin{tabular}{|c|c|c|c|}
\hline & Variables & RuralOR (95\%Cl) & UrbanOR (95\%Cl) \\
\hline Mild to moderate $\mathrm{Cl}$ & Age Group & & \\
\hline (Score: & Younger old & I & 1 \\
\hline \multirow[t]{19}{*}{ (8-23) } & Older old & $0.79(0.32-1.98)$ & $0.93(0.08-1 \mathrm{I} .01)$ \\
\hline & Sex & & \\
\hline & Male & I & I \\
\hline & Female & $3.66(1.21-11.05)^{*}$ & $0.13(0.01-37.79)$ \\
\hline & Marital Status & & \\
\hline & Married & I & 1 \\
\hline & Unmarried/widow/widower & $0.92(0.35-2.45)$ & $1.22(0.07(22.03)$ \\
\hline & Family Size & & \\
\hline & $\geq 5$ members & I & 1 \\
\hline & $<5$ members & $1.34(0.45-4.00)$ & $\mathrm{I} .08(0.05-25.40)$ \\
\hline & Number of Living Offspring & & \\
\hline & $\geq 3$ offspring & I & 1 \\
\hline & $<3$ offspring & $1.56(0.25-9.93)$ & $0.49(0.03-7.87$ \\
\hline & Living Arrangement & & \\
\hline & Living without offspring & I & I \\
\hline & Living with offspring & $0.68(0.15-3.06)$ & $1.12(0.07-17.54)$ \\
\hline & Level of Education & & \\
\hline & Educated/graduation and above & 1 & 1 \\
\hline & Non-educated/below graduation & I.34 (0.54-3.3I) & $7.60(0.4|-| 42.36)$ \\
\hline
\end{tabular}


Table Continued..

\begin{tabular}{|c|c|c|c|}
\hline \multirow[b]{2}{*}{ Mild to moderate $\mathrm{Cl}$} & Variables & RuralOR (95\%Cl) & UrbanOR (95\%Cl) \\
\hline & \multicolumn{3}{|l|}{ Age Group } \\
\hline \multirow{39}{*}{$\begin{array}{l}\text { Severe Cl } \\
\text { (Score: } \\
\leq 17 \text { ) }\end{array}$} & Occupation & & \\
\hline & Pension holder / Peasant or labor & I & I \\
\hline & Homemaker/idler & $1.56(0.29-8.56)$ & $6.6 I(0.0 I-2705.4 I)$ \\
\hline & Self Earning & & \\
\hline & Higher self earning & I & I \\
\hline & Lower self earning & $0.34(0.06-1.86)$ & $0.68(0.02-24.99)$ \\
\hline & Family Earning & & \\
\hline & Higher family earning & 1 & 1 \\
\hline & Lower family earning & $1.36(0.56-3.3 \mathrm{I})$ & $2.84(0.20-40.60)$ \\
\hline & Age Group & & \\
\hline & Younger old & I & I \\
\hline & Older old & $2.23(0.83-5.95)$ & - \\
\hline & Sex & & \\
\hline & Male & I & I \\
\hline & Female & $12.93(4.04-41.37)^{* *}$ & - \\
\hline & Marital Status & & \\
\hline & Married & I & I \\
\hline & Unmarried/widow/widower & $1.06(0.38-2.94)$ & - \\
\hline & Family Size & & \\
\hline & $\geq 5$ members & 1 & 1 \\
\hline & $<5$ members & $1.83(0.58-5.75)$ & - \\
\hline & Number of Living Offspring & & \\
\hline & $\geq 3$ offspring & 1 & 1 \\
\hline & $<3$ offspring & $4.24(0.64-28.02)$ & - \\
\hline & Living Arrangement & & \\
\hline & Living without offspring & I & I \\
\hline & Living with offspring & $2.84(0.48-16.83)$ & - \\
\hline & Level of Education & & \\
\hline & Educated/graduation and above & 1 & 1 \\
\hline & Non-educated/below graduation & $1.59(0.60-4.24)$ & - \\
\hline & Occupation & & \\
\hline & Pension holder / Peasant or labor & 1 & 1 \\
\hline & Homemaker/idler & $\mathrm{I} .44(0.25-8.18)$ & - \\
\hline & Self Earning & & \\
\hline & Higher self earning & 1 & 1 \\
\hline & Lower self earning & $0.52(0.09-2.91)$ & - \\
\hline & Family Earning & & \\
\hline & Higher family earning & 1 & 1 \\
\hline & Lower family earning & $2.08(0.80-5.40)$ & - \\
\hline
\end{tabular}

Table 6 Results of logistic regression analysis showing association between social support and social network variables and cognitive impairment categories (odds ratio and $95 \% \mathrm{Cl}$ )

\begin{tabular}{|c|c|c|c|c|}
\hline & Variables & $\begin{array}{l}\text { Rural } \\
\text { OR }(95 \% \mathrm{Cl})\end{array}$ & $\begin{array}{l}\text { Urban } \\
\text { OR }(95 \% \mathrm{Cl})\end{array}$ & $\begin{array}{l}\text { Total } \\
\text { OR }(95 \% \mathrm{Cl})\end{array}$ \\
\hline Mild to moderate $\mathrm{Cl}$ & Social Support & & & \\
\hline (Score: & Total functional & $1.01(0.99-1.02)$ & $1.04(0.98-1.09)$ & $1.00(0.99-1.01)$ \\
\hline \multirow[t]{6}{*}{ (8-23) } & Total network properties & $0.99(0.97-1.00)^{*}$ & $0.95(0.86-1.05)$ & $1.02(1.01-1.03)^{* *}$ \\
\hline & Total loss & $0.94(0.59-I .5 I)$ & - & $0.96(0.63-1.47)$ \\
\hline & Social Network & & & \\
\hline & Number of high contact role & $0.69(0.35-1.36)$ & $0.53(0.16-1.74)$ & $0.64(0.4 \mathrm{I}-\mathrm{I} .0 \mathrm{I}))^{* *}$ \\
\hline & Number of people in social network & $0.95(0.80-1.12)$ & $1.09(0.84-1.42)$ & $0.92(0.82-1.04)$ \\
\hline & Number of embedded networks & $0.31(0.06-1.52)$ & $0.74(0.13-4.15)$ & $1.24(0.56-2.74)$ \\
\hline Severe $\mathrm{Cl}$ & Social Support & & & \\
\hline \multirow[t]{7}{*}{ (Score: $<17$ ) } & Total functional & $1.01(0.99-1 .-1.03)$ & - & $\mathrm{I} .00(0.99-1.02)$ \\
\hline & Total network properties & $0.98(0.97-1.00)^{*}$ & - & $1.02(1.01-1.03)^{* *}$ \\
\hline & Total loss & $0.95(0.59-1.54)$ & - & $1.00(0.65-1.55)$ \\
\hline & Social Network & & & \\
\hline & Number of high contact role & $0.49(0.24-0.98)^{*}$ & - & $0.46(0.28-0.76)^{* *}$ \\
\hline & Number of people in social network & $1.01(0.85-1.19)$ & - & $0.96(0.85-1.09)$ \\
\hline & Number of embedded networks & $0.4 \mid(0.09-1.92)$ & - & $1.44(0.60-3.46)$ \\
\hline
\end{tabular}




\section{Discussion}

The bulk of the world's population resides in the developing countries but little is known about the prevalence rate and the risk factors of dementia or cognitive impairment in these populations. Similarities and differences in risk factors between populations of developing and developed countries may help to narrow the search for etiologic clues. ${ }^{28}$

Cognitive disability or dementia is a relatively common disorder among the elderly. Most people with cognitive disability lives in the developing countries $(60 \%$ in 2001 , estimated to rise to $71 \%$ by 2040). The rate of increase in cognitive disability over the decades is around $300 \%$ for India, whereas it is estimated to be only $100 \%$ in developed countries. ${ }^{8}$ The studies from India showed prevalence rates of cognitive disability as follows: $33.4 \%$ from Southern India, $24.4 \%$ from Western India and $13.6 \%$ from Northern India. ${ }^{29}$ The findings of the present study are rather similar in respect of the prevalence of cognitive impairment considering both locales (i.e., urban and rural). However, a significant difference exists between the two locales irrespective of sex in cognitive impairment in the present study population.

The prevalence rates from other countries were $26.8 \%$ in China, ${ }^{30}$ $58 \%$ in Japan, ${ }^{31} 22.9 \%$ in Nigeria, ${ }^{32} 84 \%$ in Italy ${ }^{33}$ and $17.3 \%$ in USA. ${ }^{34}$ Methodological differences and variance in the distribution of the aging population might possibly be important reasons behind the difference in prevalence of cognitive function.

Advancement of age is an important influencing factor of higher dementia prevalence and it is also an important cause of morbidity among geriatric populations. ${ }^{13,20,22}$ However, age did not have any significant effect on cognitive function in the present study groups except among rural females, who showed that higher age is associated with lower cognitive score or cognitive disability. It is documented by some other studies that female sex often shows higher cognitive impairment on an average. ${ }^{12,14,34,35}$ In the present study, rural study group is showing the similar result. Present study demonstrates that several socio-demographic factors affect cognitive functioning among the elderly. Notably, low education level, lower socio-economic condition and living arrangement significantly affect cognitive impairment. The role of education and occupation remained significant predictors for cognitive impairment in other studies, as well. ${ }^{36}$

A study among Bengali speaking group from West Bengal by Das et al.,${ }^{14}$ also found higher prevalence of cognitive impairment among rural study participants in comparison to urban ones. Some other earlier studies have also demonstrated the higher prevalence of cognitive impairment among rural population than that among the urban population ${ }^{11,20,37}$ which is in concordance with the findings of the present study.

Social support and network variables are shown to have significant correlation with cognitive impairment in the present study. Interestingly all the social network measures have shown significant positive correlation with cognitive score which means that higher social network values lead to higher cognitive functioning. Some studies in the same token have observed that a lack of social ties or social support increases the risk of cognitive decline ${ }^{38-40}$ a finding that matches with the observations among the rural elderly considered in the present study.

\section{Conclusion}

The present comparative study on the cognitive profile of the elderly from rural and urban West Bengal demonstrates that rural elderly of both sexes experienced greater cognitive adversities measured in terms of cognitive impairment, compared to their urban counterparts. Intuitively, among the rural elderly poor socioeconomic status leading to economic dependence coupled with low educational status could perpetuate mental health adversities in the form of problems pertaining to cognitive impairment. A well-designed epidemiological study on this aspect investigating cognitive adversities of the rural elderly of West Bengal and identification intervention points to mitigate this problem is of urgent necessity.

\section{Acknowledgements}

We express our sincere gratitude to all the study participants for their voluntary participation and kind co-operation to conduct this study. Uposoma Sinha and Abhijit Roy are gratefully acknowledged for their help and cooperation during field work. The financial support by the Indian Statistical Institute, Kolkata is gratefully acknowledged. Finally, we express our profound debt of gratitude to Professor Sandip Pal, Bangur Institute of Neurosciences, Kolkata for imparting methodological training for collection of data on cognitive function.

\section{Conflicts of interest}

Author declares there are no conflicts of interest.

\section{Funding}

None.

\section{References}

1. Jorm AF, Scott R, Cullen JS, et al. Performance of the informant questionnaire on cognitive decline in the elderly (IQCODE) as a screening test for dementia. Psychol Med. 1991;21(3):785-790.

2. Wimo A, Winblad B, Aguero-Torres H, et al. The magnitude of dementia occurrence in the world. Alzheimer Dis Assoc Disord. 2003;17(2):63-67.

3. United Nations. World Population Ageing: 1950-2050. Department of Economic and Social Affairs, Population Division, New York, USA. 2002 .

4. Bose A, Shankardass MK. Growing Old in India: Voices Reveal, Statistics Speak, B R Publishing Corporation, New Delhi, India. 2000. p. 244-246.

5. Mosby. Mosby's Medical Dictionary. (8th edn), Elsevier, Philadelphia, USA. 2009. p.2056.

6. Ritchie K, Lovestone S. The dementias. Lancet 2002;360(9347):1759-1766.

7. Prince M. Methodological issues for population-based research into dementia in developing countries. A position paper from the 10/66 Dementia Research Group. Int J Geriatr Psychiatry. 2000;15(1):21-30.

8. Ferri CP, Prince M, Brayne C, et al. Global prevalence of dementia: a Delphi consensus study. Lancet. 2005;366(9503):2112-2117.

9. Saha SP, Bhattacharya S, Das SK, et al. Epidemiological study of neurological disorder in a rural population of Eastern India. J Indian Med Assoc. 2003;101(5):299-300.

10. Rajkumar S, Kumar S. Prevalence of Dementia in the community: a rural-urban comparison from Madras, India. Australian Journal on Aging. 1996;15(2):57-61.

11. Shaji S, Bose S, Verghese A. Prevalence of dementia in an urban population in Kerala India. Br J Psychiatry. 2005;186:136-140.

12. Vas CJ, Pinto C, Panikker D, et al. Prevalence of dementia in an urban Indian population. Int Psychogeriatr. 2001;13(4):439-450. 
13. Das SK, Biswas A, Roy T, et al. A random sample survey for prevalence of major neurological disorders in Kolkata. Indian $J$ Med Res. 2006;124(2):163-172.

14. Das SK, Biswas A, Roy J, et al. Prevalence of major neurological disorders among geriatric population in the metropolitan city of Kolkata. J Assoc Physicians India. 2008;56:175-181.

15. Chandra V, DeKosky ST, Pandav R, et al. Neurological factors associated with cognitive impairment in a rural elderly population in India: the Indo-US cross-national dementia epidemiology study. $J$ Geriatr Psychiatry Neurol. 1998;11:11-17.

16. Gourie-Devi M, Gururaj G, Satishchandra P, et al. Prevalence of neurological disorders in Bangalore (India): a community based study with an urban-rural comparison. Neuroepidemiology. 2004;23(6):261-268.

17. Razdan S, Kaul RL, Motta A, et al. Prevalence and pattern of major neurological disorders in rural Kashmir (India) in 1986. Neuroepidemiology. 1994;13(3):113-119.

18. Bharucha NE, Bharucha EP, Dastur HD, et al. Pilot survey of the prevalence of neurologic disorders in the Parsi community of Bombay. Am J Prev Med. 1987;3(5):293-299.

19. Das SK, Sanyal K. Neuroepidemiology of major neurological disorders in rural Bengal. Neurology India. 1996;44(2):47-58.

20. Rajkumar S, Kumar S, Thara R. Prevalence of dementia in a rural setting: A report from India. Int J Geriatr Psychiatry. 1997;12(7):702-707.

21. Ganguli M, Ratcliff G, Chandra V, et al. A Hindi version of the MMSE: the development of a cognitive screening instrument for a largely illiterate rural elderly population in India. International Journal of Geriatric Psychiatry. 1995;10:367-377.

22. Shaji S, Promodu K, Abraham T, et al. An epidemiological study of dementia in a rural community in Kerala, India. $\mathrm{Br} J$ psychiatry. 1996;168(6):745-749.

23. Chandra V, Pandav R, Dodge HH, et al. Incidence of Alzheimer's disease in a rural community in India: the Indo-US study. Neurology . 2001;57(6):985-989.

24. Norbeck JS. Norbeck Social Support Questionnaire.Birth Defects Orig Artic Ser. 1984;20(5):45-57.

25. Cohen S, Doyle WJ, Skoner DP, et al. Social ties and susceptibility to the common cold. JAMA. 1997;277(24):1940-1944.

26. Tung-Xiung W. Reliability and validity analyses of attitude and behavior: theory, response and mediate. Public Opinion Academic Journal. 1985;1:29-53.
27. Sekaran U. Research Methods for Business - A Skill Building Approach. (3rd edn), Wiley, New York, USA. 2000.

28. Chandra V, Ganguli M, Ratcliff G, et al. Studies of the epidemiology of dementia: comparison between developed and developing countries. Aging (Milano). 1994;6(5):307-321.

29. Biswas A, Chakraborty D, Dutt A, et al. Dementia in India: a critical appraisal. J Indian Med Assoc. 2005;103(3):154,156,158.

30. Wang JJ, Snyder M, Kaas M. Stress, loneliness, and depression in Taiwanese rural community dwelling elders. Int J Nurs Stud. 2001;38(3):339-347.

31. Shibayama H, Kasahara Y, Kobayashi H. Prevalence of dementia in a Japanese elderly population. Acta Psychiatr Scand. 1986;74(2):144-151.

32. Hendrie HC, Osuntokun BO, Hall KS, et al. Prevalence of Alzheimer's disease and dementia in two communities: Nigerian Africans and African American. Am J Psychiatry. 1995;152(10):1485-1492.

33. Rocca WA, Bonaiuto S, Lippi A, et al. Prevalence of clinically diagnosed Alzheimer's disease and other dementing disorders: a door to door survey in Appignano, Macerata Province, Italy. Neurology. 1990;40(4):626-631.

34. Schoenberg BS, Anderson DW, Haerer AF. Severe dementia: prevalence and clinical features in a biracial US population. Arch Neurology. 1985;42(8):740-743.

35. Weissman MM, Myers JK, Tischler GL, et al. Psychiatric disorders (DSM-III) and cognitive impairment among the elderly in a U.S. urban community. Acta Psychiatr Scand. 1985;71(4):366-379.

36. White L, Katzman R, Losonczy K, et al. Association of education with incidence of cognitive impairment in three established populations for epidemiologic studies of the elderly. J Clin Epidemiol. 1994;47(4):363-374.

37. Bharucha NE, Bharucha EP, Bharucha AE, et al. Prevalence of Parkinson's disease in the Parsi community of Bombay, India. Arch Neurol. 1988;45(12):1321-23.

38. Bassuk SS, Glass TA, Berkman LF. Social engagement and incident cognitive decline in community - dwelling elderly persons. Ann Intern Med. 1999;131(3):165-173.

39. Seeman TE, Lusignolo TM, Albert M, et al. Social relationships, social support, and patterns of cognitive aging in healthy, high-functioning older adults: MacArthur Studies of Successful Aging. Health Psychol. 2001;20(4):243-255.

40. Yeh SCJ, Liu YY. Influence of social support on cognitive function in the elderly. BMC Health Services Research. 2003;3:1-9. 